\title{
A ATUAÇÃO DA POLÍCIA MILITAR DIANTE DO COMBATE AOS MAUS TRATOS A ANIMAIS DOMÉSTICOS
}

\author{
THE MILITARY POLICE'S PERFORMANCE IN THE FIGHT AGAINST MALT \\ TREATMENT TO DOMESTIC ANIMALS
}

\author{
Luiz Ricardo dos Santos ${ }^{1}$
}

RESUMO: Este artigo tem a finalidade de mostrar como os animais domésticos são tratados no Brasil visto sua grande participação na vida humana, mostrar a evolução dos seus direitos na legislação brasileira, mostrar as leis existentes para punição de maus-tratos animais, e também as consequências da intervenção dos humanos na vida deles. Ao longo da pesquisa, demonstra-se o importante papel dos direitos fundamentais para a proteção de direitos básicos, e a função do status de dignidade, atualmente atribuído somente aos seres humanos. Com base em uma análise das leis mais importantes sobre o assunto e das principais teorias que justificam a proteção animal, propõese uma reflexão sobre como os animais vêm sendo tratados pela legislação brasileira e pela sociedade. O objetivo é combater os maus tratos aos animais domésticos e conhecer a legislação que ampara os animais, esclarecer a população acerca dos riscos legais e mostrar o papel da polícia militar nesse combate.

Palavras-chave: Animais. Direitos Fundamentais. Proteção. Polícia Militar.

ABSTRACT: This article aims to show how animals are treated in Brazil given their great participation in human life, show the evolution of their rights in Brazilian legislation, show the existing laws for punishing animal mistreatment, and also the consequences of the intervention of humans in their lives. Throughout the research, the important role of fundamental rights for the protection of basic rights is demonstrated, and the role of the status of dignity, currently attributed only to human beings. Based on an analysis of the most important laws on the subject and the main theories that justify animal protection, we propose a reflection on how animals have been treated by Brazilian legislation and by society. The objective is to combat the mistreatment of domestic animals and to know the legislation that supports animals, to clarify the population about legal risks and to show the role of the military police in this fight.

Keywords: Animals; Rights Fundamental; Protection, Military Police.

\footnotetext{
${ }^{1}$ Policial Militar da PM-PR, Graduado do Curso de Administração de Empresas e administração Rural, Pósgraduado em Direito Ambiental e Direito Militar, Armazenagem de grãos e Segurança alimentar, Gestão Ambiental, Gestão Logística, cursando Agronomia pela Universidade do Norte do Paraná - Bandeirantes-Pr. E-mail:rikardoshow@hotmail.com.
} 


\section{INTRODUÇÃO}

A escolha pelo tema desta pesquisa "maus-tratos cometidos contra animais domésticos", deu-se especialmente por duas particularidades, primeiro pelo amor e respeito que tenho pelos animais, seres desprovidos de racionalidade, mas dotados de uma sensibilidade única, e segundo, e não menos importante, pela indignação pessoal em razão da impunidade aos agressores, que se utilizando de meios cruéis, bárbaros, expõe, sobre os olhos da sociedade, estes seres a dor e ao desamparo, na certeza de que não serão penalizados por este ato.

O Brasil não deu muita importância para os animais por há algum tempo se entender que eles não possuíam direito à liberdade, integridade física e à vida. Os animais não podem se comunicar compreensivamente com os humanos, desse modo quem irá denunciar os maus-tratos a eles cometidos? A sociedade começou a se revoltar com essas situações fazendo assim com que fossem produzidas leis mais severas.

Esse tema é de uma grande importância já que o mundo está vivendo grandes transformações e com isso os animais também são afetados. No nosso ordenamento jurídico, os animais são considerados por diversas vezes como uma mera coisa, onde nós humanos temos sua propriedade e podemos os usar, fruir e dispor como bem entender. A metodologia adotada, iniciouse pela leitura, interpretações e extrações de textos de diversas obras bibliográficas e dispositivos legais, referente ao tema proposto.

\section{INSTITUIÇÃO DA POLÍCIA MILITAR}

A Polícia Militar PM - segundo o conceito usado internacionalmente - é a corporação que exerce o poder de polícia no âmbito interno das forças armadas, garantindo a segurança, a ordem e a lei no seu seio. Geralmente, a sua ação limita-se apenas às instalações e aos membros das forças armadas, exceto quando exercem a função de Polícia Judiciária Militar, onde podem ser incluídos civis, a depender do crime cometido, nos IPMs (Inquéritos Policiais).

No Brasil a Polícia Militar tem encargos de policiamento geral de civis e militares e é conhecida como a Força Policial que realiza o policiamento ostensivo, preventivo, repressivo imediato e de preservação da ordem pública em todo o território brasileiro, sendo que cada Estado e o Distrito Federal possui sua própria Polícia Militar, subordinadas ao Governador do Estado a que pertencem. A Polícia Militar do Estado de São Paulo é a segunda maior força militar do Brasil, perdendo em número de efetivo somente para o exército.

Em tempo de guerra, além das anteriores missões, a polícia militar também se pode encarregar da defesa imediata de infraestruturas estratégicas, da proteção de altas autoridades 
militares e civis, da administração dos prisioneiros de guerra, da regulação do tráfego rodoviário e da segurança pública nas regiões sujeitas a administração militar. Em muitos países, as forças armadas dispõem de um sistema judiciário independente do sistema judiciário civil, podendo administrar as suas próprias prisões e tribunais, os quais se regulam por legislação distinta.

No âmbito dos sistemas judiciários militares de alguns países, inclusive já acontece isso no Brasil, pode competir à polícia militar a função de polícia judiciária, encarregando-se da investigação de crimes militares ou de crimes comuns (tais como roubos, homicídios ou tráfico de droga) cometidos por militares.

Em diversas forças armadas, o comandante da polícia militar tem o título de "preboste", título que em alguns exércitos também é utilizado para designar o próprio serviço de polícia militar.

$\mathrm{Na}$ maioria dos países, os membros da polícia militar distinguem-se dos restantes militares pelo uso de distintivos especiais, como são os casos de cinturões brancos, de braçais e capacetes com as siglas "PM", usados pelas polícias militares de inúmeros países. Outro distintivo tradicional eram os gorjais, placas metálicas com o emblema nacional, usadas penduradas no pescoço pelos membros da polícia militar alemã, até ao final da Segunda Guerra Mundial.

Em algumas forças armadas, o termo "polícia militar" aplica-se exclusivamente às polícias das suas componentes terrestres, designando-se as polícias das outras componentes por termos diferentes como "polícia naval" ou "polícia aérea".

As missões específicas das polícias militares variam de país para país, de acordo com a organização das suas forças armadas e da sua legislação. A maioria dos países da OTAN segue a doutrina estabelecida pela STANAG 2085 (Polícia Militar Combinada da OTAN), a qual também é seguida por muitos países não pertencentes àquela organização. Em termos gerais, as missões compreendem:

- Assegurar o respeito pela lei e pelos regulamentos militares;

- Manutenção da ordem e da disciplina no seio das forças armadas;

- Prevenção e investigação criminal;

- $\quad$ Fiscalização e controle do trânsito rodoviário nas áreas militares;

- $\quad$ Segurança de instalações militares e estratégicas;

- $\quad$ Escolta de comboios militares;

- Segurança e proteção pessoal de autoridades militares e civis;

- Guarda de presos sujeitos à justiça militar;

- Evacuação, administração e guarda de prisioneiros de guerra;

- $\quad$ Controle de distúrbios;

- Perseguição e captura dos foragidos à justiça militar; 
- Controle civis extraviados em zona de guerra;

- Realização de ações de cooperação civil-militar (CIMIC);

- Garantia da segurança pública em áreas sujeitas a administração militar;

- Segurança de retaguarda em zona de guerra.

A Polícia Militar é uma Instituição da administração pública, que visa pôr em ação as limitações que a lei impõe à liberdade dos indivíduos e dos grupos para salvaguardar e preservar a Ordem Pública. A definição do termo "polícia", no decorrer dos séculos, passou por diversas definições e conceituações, dependendo da doutrina jurídica que se conceitua.

Para Silva (apud JESUS, 2019, p. 96) "a palavra polícia está correlacionada com a segurança e tem sua origem no grego polis, o que significa o ordenamento político do Estado”.

Para Jesus (2019, p. 95), "no Estado moderno, seu significado chegou a compreender toda a atividade da administração pública onde se identificava com um Estado de Polícia, com que se designava um ordenamento em que toda a função administrativa era indicada com o termo de polícia”.

Segundo o autor, no início do século XIX, o termo polícia voltou a ter um significado mais restrito, passando a identificar-se com a atividade tendente a assegurar a defesa da comunidade contra os perigos internos, quando estes estavam representados nas ações e situações contrárias à ordem e à segurança pública (JESUS,2019).

A instituição militar é um órgão pertencente à Administração Pública Direta do Estado, destinada a realizar o funcionamento da segurança pública. $\mathrm{O}$ art. $144,85^{\circ}$ da Constituição Federal de 1988 preceitua a composição das polícias, suas funções e campos de atuação. A polícia militar tem por atividade a vigilância ostensiva e a garantia da ordem pública, ou seja, tem por destinação atuar na prevenção de infrações penais.

As agências executivas institucionalizadas como não judiciais têm a função, no sistema penal, de aparelho de vigilância de natureza civil, entretanto existe uma militarização desses órgãos.

\section{I POLÍCIA MILITAR DO PARANÁ}

A Polícia Militar do Paraná (PMPR) integra o sistema de segurança pública e defesa social do Brasil, e tem por missão a preservação da ordem pública, o policiamento ostensivo e a execução de atividades de defesa civil no estado do Paraná, além de outras atribuições previstas na legislação federal e estadual. Seus integrantes, incluindo-se os membros do Corpo de Bombeiros do Paraná, são denominados militares dos Estados, e a corporação é força auxiliar e reserva militar do Exército Brasileiro. 
A Polícia Militar se identifica pelo uniforme que usa e exerce, com eficiência e eficácia, a função de polícia preventiva em toda a sua plenitude, evitando, com a sua presença, a perpetração do delito e guardando o emprego de medida repressiva para a última instância.

Como agentes da Lei, seus membros têm tombado no solo sem vida, numa demonstração inequívoca de que a missão policial militar é árdua, complexa, dignificante e pode até mesmo custar o sacrifício da própria vida.

Não se encontra no mapa do Estado um lugar onde não haja tombado, em holocausto ao dever, o soldado de polícia, inscrevendo, a sangue vivo, a odisseia magnífica da dor e do sacrifício nessas jornadas de todo o dia, obscura é verdade, mas de um profundo e belo sentido de defensor da vida e dos bens da gente laboriosa, das cidades e dos sertões, constantemente ameaçados pelo flagelo do banditismo.

O seu passado, cheio de tradições, está vinculado à própria história do Paraná. E esta ensina, e confirma, que a Corporação sempre esteve presente e atuante nos momentos decisivos do nosso Estado, em harmonia com as aspirações populares e as melhores recordações do povo paranaense.

Crescendo paralelamente com o desenvolvimento do Estado, a Polícia Militar vem assinalando, nas dobras do pavilhão que defende, com denodo de bravos, os feitos de suas empreitadas vitoriosas, nos domínios da paz, no terreno das dificuldades e nos campos de batalha.

\section{ANIMAIS E OS MAUS- TRATOS}

Animais domésticos são aqueles que pertencem a um lar, ou seja, estes seres se desenvolvem na companhia de seus donos. Já os animais selvagens, ou silvestres, são aqueles que vivem em seu habitat natural, sem qualquer intervenção dos seres humanos. Estes animais podem também desempenhar umas funções específicas em seus lares, como é o caso dos cães de guarda, que garantem a segurança da casa e uma noite tranquila aos seus donos. Outros exemplos disto são os gatos, que caçam e mantém a casa livre de roedores, entre outros animais. Os cães guias de deficientes visuais, que além de desempenhar tarefas de grande responsabilidade à segurança de seu dono, ainda podem trazer alegria e afeto ao mesmo. São considerados propriedade de seus donos e os abandonados estão sujeitos à apropriação.

Tem-se o entendimento minoritário da doutrina corroborado por Edna Cardozo Dias, no sentido de que "os animais são sujeitos titulares de direitos civis e constitucionais, dotados, pois, de uma espécie de personalidade sui generes, típica e própria à condição” (DIAS,2010).

Assim sendo, não se pode afirmar que os animais possuem uma personalidade característica dos humanos, mas como sujeitos de direito reconhecidos e tutelados, acabam reunindo atributos para que possam ser colocados numa situação jurídica peculiar, sendo dotados de uma personalidade anômala. 
Os animais são seres integrantes do meio ambiente e sua interferência no ecossistema é essencial para auxiliar no equilíbrio do mesmo, tornando mais sadia à qualidade de vida dos seres humanos, independentemente de sua função ecológica.

A criação da Lei $9.605 / 98$, lei de crimes ambientais deu-se no sentido de dar maior proteção ao meio ambiente, proteção esta indispensável para a preservação de nossa fauna e flora, sendo que graças a Lei em cito, os crimes contra a fauna ganharam maior espaço na mídia e reconhecimento político.

Para Vladimir Passos de Freitas e Gilberto Passos de Freitas "a nova lei de crimes ambientais buscou trazer uma redação onde a punibilidade é mais branda, porém mais aplicável, tentando desta maneira transtornar o problema ocorrido com a antiga Lei 5.197/67 (FREITAS, et al., 2011).

Segundo os autores as normas que tratavam dos crimes ambientais sobre a proteção da fauna eram repletas de leis severas sem aplicabilidade no mundo jurídico, sendo interpretadas por muitos magistrados como severas de mais tendo em vista a gravidade do crime praticado, e deixada de serem aplicada sobre este argumento.

A já mencionada lei traz em seus artigos 29 a 37 a proteção à fauna enquanto bem ambiental, no sentido de os animais não serem sujeitos de direitos diretamente esculpidos na norma fundamental, mais sim são tutelados pela Constituição da República Federativa do Brasil de 1988, e 461 possuem a tutela penal contra os crimes praticados contra eles. É, portanto, com aplicação da tutela criminal dos bens ambientais que devemos interpretá-la em face da fauna, verificando suas finalidades ecológicas, científicas recreativas e culturais (FIORILLO, 20I6).

Este artigo revogou de forma tácita a contravenção de crueldade praticada contra animais prevista no art. 64 da Lei de Contravenções Penais.

Tem-se como sujeito ativo do crime de maus tratos, qualquer pessoa imputável, portanto trata-se de crime comum. Mais em relação a prática deste crime ser cometido por pessoa jurídica existem posicionamento divergente por parte da doutrina.

Paulo José da Costa Filho e Édis Milaré "adotam a corrente de que o crime só poderá ser praticado por pessoa física” (MILARÉ, et al., 20II). Já para Guilherme de Souza Nucci “o crime pode ser praticado por pessoa jurídica" (NUCCI, 2016).

Na visão de Édis Milaré e Paulo José da Costa Júnior “o sujeito passivo do crime é a coletividade em geral, e não o animal que é objeto material da conduta, podendo ser sujeito passivo a União quando se tratar de animais silvestres" (MILARÉ, et al., 2oII). 
Já para Guilherme de Souza Nucci “o Estado não figura como sujeito passivo do crime, mais apenas a sociedade possuiria esta legitimação passiva por ter o interesse em resguardar o meio ambiente" (NUCCI,2016).

Portanto, pode-se disser que a sociedade seria o sujeito passivo principal, enquanto o Estado figuraria como sujeito passivo frequente por ter a responsabilidade da tutela ambiental.

Para José Henrique Pierangeli “o art. 32 da lei 9.605/98 revogou a legislação anterior que tratava da matéria" (PIERANGELI, 20I0).

Para Édis Milaré e Paulo José da Costa Junior a prática de abuso contra animal configurase:

Configura a prática de ato de abuso quando se exige do animal um esforço acima de suas forças extrapolando seus limites, sendo o caso daquele que cavalga por muitas milhas, sem dar necessário repouso ao animal, ou aquele que exige dos jumentos atrelados a carroça que puxem cargas pesadas em longos trajetos (MILARÉ, et al., 20II).

Em sentido contrário Guilherme de Souza Nucci "entende que o dispositivo em relação à prática dos atos de abuso e maus-tratos, é inaplicável, eis que trata de forma genérica e ampla. Sua aplicação ensejaria desrespeito ao princípio da taxatividade, fruto da legalidade" (NUCCI, 2016).

Ainda assevera Nucci "que nestas previsões legais insere-se qualquer tipo de condutas podendo-se citar, deixar animal sem água por um dia ou priva-lo de contato com outros de sua espécie" (NUCCI,2016).

Assim, tais condutas exemplificadas acima não ensejariam a aplicação do dispositivo legal, devendo ser analisada a cada caso concreto.

Contudo, para Diomar Ackel Filho "é difícil relacional todos os atos que possam implicar em maus tratos, daí ter o legislador optado por um gênero, cabendo ao intérprete, no caso concreto, verificar se a ação ou omissão foi imprópria, ou cruel e se em virtude dela, o animal foi molestado".165

Portanto, para Édis Milaré "a prática de maus-tratos consiste no castigo excessivo e desnecessário do animal” (FILHO,20II).

Em relação aos maus-tratos, pode-se exemplificar os rodeios, farra do boi, experiências dolorosas e vivissecção, entre outras. Podendo-se citar como exemplo, deixar um cachorro permanentemente fechado em local pequeno insuficiente para que ele possa se movimentar livremente, sem ventilação e sem o mínimo de higiene (FREITAS, 2016).

Contudo, nesta relação maus-tratos e costumes por muitas vezes esta prática infelizmente passa a ser justificável. Já no aspecto ferir, tem-se a lesão ao animal como exemplo pode-se citar a conduta do agente quando com a ação exagerada ao açoitar o cavalo, causando-lhe ferimentos. E em relação a mutilar o animal, tem-se a conduta em que a agressão é totalmente descabida e 
desproporcional ao ponto de retirar partes do corpo do animal, geralmente um membro (FREITAS,2016).

Édis Milaré e Paulo José da Costa Junior “entendem que o delito já se configura em evidenciam a mutilação em um exemplo muito claro quando os circos ao retirar garras e dentes dos animais para sua exibição expõem os animais a um excessivo sofrimento” (MILARÉ, et al., 2oII).

Contudo, como a Lei Penal não adota a responsabilidade objetiva, será nestes casos, preciso verificar se o agente ágil com dolo, tendo em vista o crime ser um crime de conduta comissiva.

Deste modo, o fato típico em discussão poderá gerar algumas dúvidas sobre sua consumação quando ocorrer à morte de um animal doméstico. Tendo em vista que para os animais silvestres existe um tipo penal específico na lei de crimes ambientais (art. 29) que utiliza o verbo matar, contudo, no art. 32 da lei em comento, não faz menção do referido verbo. Assim para que se alcance a morte do animal doméstico ou domesticado, e se reconheça a consumação do delito, será imprescindível que os maus-tratos, ferimentos e mutilações acarretem a morte do animal, pode-se citar como exemplo, desferir golpes de faca, ou apedrejamento ou até mesmo utilizando o emprego de veneno, passando inevitavelmente o animal por tratamento que gera intenso sofrimento (FREITAS,2016).

Ressalta-se, que o crime tentado é admissível, neste aspecto o agente pode ser impedido antes de praticar o ato lesivo ao animal, bem como será admitida perícia, pois, em regra só o exame no animal poderá confirmar quais as lesões causadas pelo ato praticado. Estas condutas podem receber pena de três meses a um ano de detenção e multa cumulativamente, sendo a ação penal pública incondicionada e de iniciativa do Ministério Público.

Com o objetivo de frear os maus-tratos contra animais, o Presidente Jair Bolsonaro sancionou no dia 29 de setembro de 2020, a Lei 1.095/2019, que aumenta a punição para quem praticar ato de abuso, maus-tratos, ferir ou mutilar animais. Altera a Lei n. ${ }^{0}$ 9.605, de 12 de fevereiro de 1998, para aumentar as penas cominadas ao crime de maus-tratos aos animais quando se tratar de cão ou gato. A legislação abrange animais silvestres, domésticos ou domesticados, nativos ou exóticos, incluindo, aí, cães e gatos, que acabam sendo os animais domésticos mais comuns e as principais vítimas desse tipo de crime. A nova lei cria um item específico para esses animais. Estabelece pena de reclusão de 2 a 5 anos e proibição de guarda quando praticado ato de abuso, maus-tratos ou mutilação contra cães e gatos.

A lei sancionada também prevê punição a estabelecimentos comerciais e rurais que facilitarem o crime contra animais. O texto define, a prática de abuso e maus tratos a animais será punida com pena de reclusão de dois a cinco anos, além de multa e a proibição de guarda. Atualmente, 
o crime de maus-tratos a animais consta no artigo 32 da Lei de Crimes Ambientais 9.605/98 e a pena previa de três meses a um ano de reclusão, além de multa.

Segundo o Instituto Brasileiro de Geografia e Estatística (IBGE), existem, no Brasil, 29 milhões de domicílios com cães e II milhões, com gatos.

É preciso lembrar que a Constituição Federal assegura o meio ambiente ecologicamente equilibrado como um direito de todos (art. 225), e a proteção, e a defesa dos animais, bem como a vedação à crueldade, são expressamente previstas no inciso VII do § I.음 do art. 225. Nesse dispositivo, estabeleceu-se a incumbência do Poder Público de proteger a fauna e a flora, vedadas, na forma da lei, as práticas que coloquem em risco sua função ecológica, provoquem a extinção das espécies ou submetam os animais a crueldade. Reconhece a ordem constitucional o valor inerente a formas de vida não humanas, com a garantia, ao animal, do direito de não ser submetido a ações cruéis em uma dimensão jurídica protetora de sua vida e dignidade. O Supremo Tribunal Federal, nesse sentido, acumula precedentes sobre a proibição de práticas cruéis a animais.

\section{CONCLUSÃO}

O trabalho da Polícia Militar tem como finalidade o coibir e o dissuadir ações que representem ameaças ou crimes contra os animais domésticos. Zelar pelo cumprimento da legislação vigente no qual diz respeito aos maus tratos a animais, orientar a população acerca da legislação atual e da importância do seu cumprimento e desenvolver programas de educação junto à comunidade também são tarefas realizadas pela polícia Militar.

A Policia Militar do estado do Paraná atua em todo o Estado em parceria com o Ministério Público e as ONGs de Proteção a Animais no combate aos maus tratos e repreende veementemente tal conduta criminosa, atua de maneira ostensiva e preventiva, em casos de constatações de tais delitos, os infratores são apresentados para Polícia Judiciária para os devidos procedimentos legais, tais cumpram-se as penas impostas por determinada conduta criminosa.

Temos muito a progredir nesta seara, o respeito aos animais, que possuem tutela constitucional, este tema precisa de atenção da sociedade, inadmissível um país como o Brasil ser tão retrogrado socialmente quando o assunto é a punição dos agressores de animais, atualmente questões culturais não são admissíveis para subsidiar a manutenção da impunidade.

É possível afirmar, que com o desenvolvimento desse trabalho, percebe-se que, na prática, muitos animais sofrem com maus tratos e atos de crueldade, e que aplicação da lei ainda é muito precária. Nota-se, portanto, que os seres humanos, embora estejam evoluindo no que tange a proteção dos animais, ainda criam leis que regulamentam situações em que é possível a exploração de animais. 


\section{REFERÊNCIAS}

BECHARA, Érica. A proteção da fauna sob a ótica constitucional. Dissertação de mestrado orientado pelo Professor Doutro Antônio Pacheco Fiorillo, PUC-SP, 2013, p. 72.

BICALHO, Pedro Paulo Gastalho. Subjetividade e abordagem policial: por uma concepção de direitos humanos onde caibam mais humanos. $198 \mathrm{fls}$. Tese (Doutorado em Psicologia). Universidade Federal do Rio de Janeiro. Faculdade de Psicologia. Rio de Janeiro, 2015.

BRASIL. Lei 9.605 de 12 de fevereiro de 1998 - art. 32. Disponível em: http://www.planalto.gov. br/ccivil_03/leis/L9605.htm acesso em: o9 de dez de 2020.

CUSTÓDIO, Helita Barreira. Apud. Edna Cardozo Dias. A tutela jurídica dos animais. Belo Horizonte, Mandamentos, 2010, p.156.

DIAS, Edna Cardozo. A tutela jurídica dos animais. Belo Horizonte: mandamentos, 2010, p. ro4.

FERREIRA, Aurélio Buarque de Holanda. Novo dicionário da Língua Portuguesa. Rio de Janeiro, 2. ed., melhoramentos, p. 189.2012.

FILHO, Diomar Ackel. Direito dos animais. São Paulo. Themes, 20II, p.I5ı

FIORILLO, Celso Antonio Pacheco. Curso de direito ambiental brasileiro. Io ed. São Paulo: Saraiva, 2019, p. 184 .

FIORILlO, Celso Antonio Pacheco. Curso de direito ambiental brasileiro - 7. ed. São Paulo: Saraiva, 2016. p. 527.

FOUCAULT, Michel. Vigiar e Punir: História da Violência nas Prisões. 20 ed. Petrópolis: Vozes, 2015 .

FREITAS, Vladimir Passos de e Gilberto Passos de. Crimes contra a natureza: Rio de Janeiro: Revista dos Tribunais $7^{-a}$ ed, Ano 2011. p. 85 .

FREITAS, Vladimir Passos de e FREITAS, Gilberto Passos de. Crimes contra a natureza. 8. ed. São Paulo. 20I6. p. IIo-III.

JESUS, Iracema Oliveira de. Racismo institucional: causas e efeitos na educação da rede pública. Monografia. Graduação em Pedagogia. UNEB. Salvador, 2016. 
MILARÉ, Édis e JUNIOR, Paulo José da Costa. Direito penal ambiental. Comentário a lei 9.605/98. Campinas, Milenium, p.86.20II

NUCCI, Guilherme de Souza. Leis penais e processuais penais comentadas. São Paulo, 2016, p.5I4.

PIERANGELI, José Henrique. Meio ambiente: parecer em direito penal ambiental. Síntese de direito penal e processual penal, n. 3, ago./set. 2010, p.151.

RODRIGUES, Silvio. Direito civil - parte geral. São Paulo: Saraiva, 34. ed 2013, p

Major RR Antunes http://www.pmpr.pr.gov.br/Pagina/Historico

https://www.gov.br/pt-br/noticias/meio-ambiente-e-clima/2020/o9/sancionada-lei-que-aumentapunicao-para-maus-tratos-de-animais 